\title{
Hubungan Motivasi Kerja terhadap Perilaku Caring Perawat di Ruang Rawat Inap Rumah Sakit Jiwa Tampan Provinsi Riau
}

\section{The Relation Between Working Motivation and Nurse Caring in Tampan Mental Health Hospital Of Riau Province}

\author{
Siti Khodijah, Erna Marni
}

Prodi Ilmu Keperawatan STIKes Hang Tuah Pekanbaru.

\begin{abstract}
ABSTRAK
Caring merupakan fenomena menyeluruh yang mampu mempengaruhi cara manusia berpikir, merasa dan mempunyai hubungan dengan sesama. Perilaku caring dapat terwujud karena adanya dorongan baik dari internal maupun eksternal. Penelitian ini bertujuan untuk mengetahui hubungan motivasi kerja terhadap perilaku caring perawat di ruang rawat inap Rumah Sakit Jiwa Tampan Provinsi Riau. Jenis penelitian kuantitatif , pendekatan Crossectional. Tehnik pengambilan sampel dengan total sampling, jumlah sampel sebanyak 56 orang perawat pelaksana diruang rawat inap, alat pengumpulan data dalam bentuk kuesioner dan lembar observasi. Analisa yang digunakan adalah analisa univariat dan analisa bivariat dengan menggunakan uji chi-square. Hasil penelitian diketahui adanya hubungan secara signifikan antara motivasi kerja terhadap perilaku caring perawat di ruang rawat inap dengan $(p$ value $=0,001)$. Diharapkan kepada Bagian Diklit dan Bagian Bidang Keperawatan agar mengadakan pelatihan-pelatihan untuk perawat yang berkaitan dengan perilaku caring dalam melaksanakan asuhan keperawatan sehingga dapat meningkatkan mutu pelayanan keperawatan kepada klien.
\end{abstract}

Kata Kunci : Perilaku Caring, Motivasi Kerja

\section{ABSTRACT}

Caring is a comprehensive phenomenon that can affect the way people think, feel and have a relationship with fellow. Caring behavior can be realized due to lack of motivation of both internal and external. This research aims to determine the relationship of work motivation on nurses caring behaviors in the patient room at Tampan Pshyciatric Hospital, Riau Province. Type a descriptive study with cross sectional correlation. Sampling technique with non-probability sampling sample size by 56 respondents, measuring tools in the form of questionnaires and observation sheets. The analysis used is univariate and bivariate analysis using chi-square test. The result shows revealed a significant relationship between work motivation on nurse caring behaviors in the patient room with ( $p$ value $=0.001)$. Expected to Section Diklit and nursing fields section to hold trainings for nurses related to caring behavior in implementing nursing care so as to improve the quality of nursing care to clients.

Keywords: Work Motivation, Caring Behavior

\section{PENDAHULUAN}

Kesehatan jiwa merupakan salah satu dari empat masalah kesehatan utama di negara-negara maju. Sehat jiwa merupakan keadaan tidak gangguan jiwa. Sehat jiwa adalah keadaan individu yang memiliki cara komunikasi, management perilaku, dan bertindak yang bersifat positif yang menggambarkan keselarasan dan keseimbangan kejiwaan serta mencerminkan kedewasaan kepribadian seorang individu (WHO, 2009). Pernyataan ini didukung oleh UU Kesehatan Jiwa No. 3 Tahun 1996, kesehatan jiwa merupakan kondisi yang memungkinkan perkembangan fisik, intelektual, emosional secara optimal dari seseorang dan perkembangan ini selaras dengan orang lain. Kesehatan jiwa sangat erat kaitannya dengan tingkah laku seseorang. Hal ini yang dapat menggambarkan seseorang tersebut sehat jiwa atau mengalami gangguan kesehatan jiwa.

Menurut WHO (2009), masalah gangguan jiwa di seluruh dunia sudah menjadi masalah yang sangat serius. WHO menyatakan ada satu dari empat orang di dunia mengalami masalah mental, diperkirakan ada sekitar 450 juta orang di dunia yang mengalami gangguan kesehatan jiwa. Delapan dari sepuluh orang penderita gangguan jiwa ini tidak mendapatkan perawatan, dimana sepertiganya berdomisili di negaranegara berkembang. Departemen Kesehatan (2010) menyatakan lebih dari 28 juta orang penduduk Indonesia menderita gangguan kesehatan jiwa. 
Besarnya pertambahan penderita gangguan jiwa, menyebabkan diadakannya beberapa perubahan di bidang pelayanan di setiap Rumah Sakit Jiwa di Indonesia, terutama keperawatan jiwa. Hal ini ditinjau dari aspek pelayanan yang langsung dengan pasien adalah perawat. Perawat dikatakan sebagai salah satu faktor pendukung suksesnya pelaksanaan standar asuhan keperawatan. Menurut DepKes R.I (2011), perawat jiwa di Indonesia memiliki peran utama dalam meningkatkan kesembuhan pasien. Selama 24 jam perawat berinteraksi kepada pasien dan mengaplikasikan kemampuan yang dimilikinya baik secara fisiologis maupun psikologis sesuai dengan kebutuhan pasien. Selama melakukan interaksi dengan pasien diperlukan motivasi dan perilaku caring yang dapat mendukung proses keperawatan.

Caring adalah fenomena universal yang mempengaruhi cara manusia berpikir, merasa, dan mempunyai hubungan dengan sesama. Watson menyatakan caring dapat diartikan sebagai suatu kemampuan untuk berdedikasi bagi orang lain, pengawasan dengan waspada, perasaan empati pada orang lain dan perasaan cinta atau menyayangi (Potter dan Perry, 2009). Penelitian deskriptif di Provinsi Sumatra Utara mendapatkan gambaran tentang perilaku caring perawat dalam memberikan asuhan keperawatan kepada pasien di Rumah Sakit Jiwa Daerah Provinsi Sumatra Utara, Medan. Sebanyak 36 responden sampel diambil dari perawat yang bekerja di Rumah Sakit Jiwa Daerah Provinsi Sumatra Utara. Hasil penelitian menunjukkan bahwa 58,3\% responden menunjukkan perilaku caring yang cukup, dan 41,7\% responden memperlihatkan perilaku caring yang baik dalam memberikan asuhan keperawatan kepada pasien gangguan jiwa di Rumah Sakit Jiwa Daerah Provinsi Sumatra Utara, Medan (Irawan, 2010).

Setiap tindakan yang dilakukan oleh perawat untuk berperilaku caring sangat erat kaitannya dengan motivasi (niat). Nursalam (2012) menyatakan, motivasi adalah pemberian atau penimbulan motif, dapat pula diartikan hal atau keadaan menjadi motif. Penelitian yang dilakukan di Rumah Sakit Jiwa Daerah Provinsi Sumatera Utara, Medan tentang Pengaruh Motivasi Berprestasi terhadap Kinerja Perawat dalam Asuhan Keperawatan Pasien Gangguan Jiwa, Hasil penelitian menunjukkan dari lima sub variabel motivasi berprestasi ada empat variabel yang berpengaruh terhadap kinerja perawat yaitu promosi $(\mathrm{p}=0.000)$, tantangan $(\mathrm{p}=0.000)$, imbalan $(\mathrm{p}=0.016)$ dan pengakuan $(\mathrm{p}=0.012)$ sedangkan variabel prestasi kerja tidak berpengaruh terhadap kinerja perawat (Amelia, 2009).

Motivasi kerja perawat sangat mempengaruhi perilaku caring perawat dan menjadi sangat penting dalam mempengaruhi kualitas pelayanan dan kepuasan pasien terutama di rumah sakit, dimana kualitas pelayanan menjadi penentu citra institusi pelayanan yang nantinya akan dapat meningkatkan kepuasan pasien dan mutu pelayanan (Potter dan Perry, 2009 )

Penelitian ini bertujuan untuk melihat apakah ada hubungan antara motivasi kerja terhadap prilaku Caring perawat di Ruang Rawat Inap Rumah Sakit Jiwa Tampan Provinsi Riau tahun 2013.

\section{METODOLOGI}

Penelitian ini bersifat kuantitatif analitik dengan jenis desain "Cross Sectional". Dalam penelitian ini yang dijadikan populasi adalah semua perawat yang ada di lima ruangan rawat inap RSJ Tampan Provinsi Riau yang berjumlah 65 orang. Sampel yang digunakan dalam penelitian ini adalah perawat yang ada di lima ruangan rawat inap RSJ Tampan Provinsi Riau yang berjumlah 56 orang dengan metode pengambilan total sampling.

Pengumpulan data dilakukan dengan cara memberikan kuesioner kepada responden, meliputi motivasi kerja yang terdiri dari 24 pernyataan yang diteliti dengan menggunakan skala likert, yaitu dengan rentang nilai 1 jika jawaban sangat tidak setuju, nilai 2 jika jawaban tidak setuju, nilai 3 jika jawaban setuju dan nilai 4 jika jawaban sangat setuju untuk pernyataan positif. Pernyataan positif terletak pada pernyataan nomor $1,2,4,6,7,8,11,12,15,18,21$, dan 24. Rentang nilai 4 jika jawaban sangat tidak setuju, nilai 3 jika jawaban tidak setuju, nilai 2 jika jawaban setuju dan nilai 1 jika jawaban sangat setuju untuk pernyataan negatif. Pernyataan negatif terletak pada pernyataan nomor $3,5,9,10,13,14,16,17,19$, 20, 22, dan 23. Kemudian pengisian lembar observasi yang dilakukan peneliti tentang perilaku caring perawat yang terdiri dari 15 pernyataan tindakan dengan menggunakan skala guttman yang memiliki rentang nilai 1 jika jawaban iya dan nilai 0 jika tidak yang akan di observasi di lima ruang rawat inap rumah sakit jiwa.

Pengolahan data dilakukan dengan menggunakan sistem komputerisasi. Analisa data dilakukan secara bertahap yaitu Analisa Univariat yaitu seluruh variabel disusun dalam bentuk distribusi frekuensi yang meliputi karakteristik responden, motivasi kerja (variabel independen) dan perilaku caring perawat (variabel dependen). Sedangkan analisa bivariat dilakukan untuk mengetahui hubungan motivasi kerja dengan perilaku caring perawat. Analisis data menggunakan uji Chi Square.

\section{HASIL}

\section{Analisa Univariat}

Hasil penelitian diperoleh bahwa sebagian besar jenis kelamin responden adalah perempuan yaitu 
48 orang $(85,7 \%)$, umur responden sebagian besar adalah umur antara 31-51 tahun yaitu 38 orang $(67,9 \%)$, sebagian besar pendidikan responden adalah DIII Keperawatan yaitu 40 orang $(71,4 \%)$, dan lama bekerja responden yang paling banyak adalah antara 15 tahun yaitu 22 orang $(39,3 \%)$.

Berdasarkan hasil penelitian ini diperoleh bahwa untuk motivasi kerja perawat di ruang rawat inap Rumah Sakit Jiwa Tampan Provinsi Riau dapat disimpulkan bahwa banyak responden yang memiliki motivasi kerja tinggi yaitu berjumlah 30 orang $(53,6 \%)$. Sedangkan untuk perilaku caring perawat di ruang rawat inap Rumah Sakit Jiwa Tampan Provinsi Riau dapat disimpulkan bahwa sebagian besar responden yang memiliki perilaku caring yaitu bejumlah 29 orang $(51,8 \%)$.

\section{Analisa Bivariat}

Analisa ini dilakukan untuk mengetahui hubungan dua variabel yaitu variabel independen (motivasi kerja) dengan variabel dependen (perilaku caring perawat).

Tabel 1

Hubungan Motivasi Kerja Terhadap Perilaku Caring Perawat di Ruang Rawat Inap

\begin{tabular}{|c|c|c|c|c|c|c|}
\hline \multirow{4}{*}{$\begin{array}{l}\text { Motivasi } \\
\text { kerja } \\
\text { perawat }\end{array}$} & \multicolumn{4}{|c|}{ Perilaku caring } & \multirow{2}{*}{\multicolumn{2}{|c|}{$\begin{array}{l}\text { OR P value } \\
95 \% \\
\text { CI }\end{array}$}} \\
\hline & & & & & & \\
\hline & Caring & \multicolumn{2}{|c|}{$\begin{array}{l}\text { Tidak } \\
\text { caring }\end{array}$} & Jumlah & & \\
\hline & $\%$ & $\mathrm{n}$ & $\%$ & $\mathrm{~N} \%$ & & \\
\hline Tinggi & 2273,3 & 8 & 26,7 & $30 \quad 100$ & 746 & \\
\hline Rendah & 26,9 & 19 & 73,1 & $26 \quad 100$ & $(2,28-$ & 0,001 \\
\hline Jumlah & 2951,8 & 27 & 48,2 & $56 \quad 100$ & $-24,4)$ & \\
\hline
\end{tabular}

Tabel menunjukkan bahwa dari 56 orang responden yang memiliki motivasi kerja tinggi dengan perilaku caring sebanyak 22 orang atau $73,3 \%$, sedangkan responden yang memiliki motivasi kerja tinggi dengan perilaku tidak caring sebanyak 8 orang atau $26,7 \%$. Untuk responden yang memiliki motivasi kerja rendah dengan perilaku caring sebanyak 7 orang atau $26,9 \%$, sedangkan responden yang memiliki motivasi kerja rendah dengan perilaku tidak caring sebanyak 19 orang atau $73,1 \%$.

Dari hasil analisa didapatkan nilai $p=<0,005$ terdapat hubungan yang signifikan antara motivasi kerja terhadap perilaku caring perawat di ruang rawat inap Rumah Sakit Jiwa Tampan Provinsi Riau Tahun 2013. Hasil analisis diperoleh nilai $\mathrm{OR}=7,46$ artinya perawat yang memiliki motivasi kerja rendah mempunyai resiko untuk memiliki perilaku tidak caring 7,4 kali lebih besar dibandingkan dengan perawat yang memiliki motivasi tinggi.

\section{PEMBAHASAN}

Berdasarkan hasil analisa yang telah dilakukan, dapat disimpulkan bahwa sebagian besar responden berjenis kelamin perempuan yang berjumlah 48 orang $(85,7 \%)$. Hal ini menunjukkan bahwa profesi perawat lebih banyak disandang perempuan. Perawat harus memiliki naluri keibuan (mother instinct) dalam memenuhi segala kebutuhan klien. Dalam Potter dan Perry (2009) menyatakan bahwa perlakuan perawat yang lembut, sejalan dengan kontak mata,kepedulian terhadap masalah klien, dan hubungan fisik mengekspresikan fokus pada satu individu merupakan pendekatan yang nyaman. Pernyataan ini didukung oleh Wahyuni (2010) menyatakan bahwa perawat perempuan lebih sabar dan teliti sesuai naluri alamiah yang dimilikinya.

Hasil penelitian diperoleh umur responden yang terbanyak berada pada rentang umur 31-51 tahun yang berjumlah 38 orang $(67,9 \%)$. Pernyataan ini didukung oleh Wahyuni (2010) bahwa pada umur dewasa pertengahan, perawat lebih fokus pada karir sebagai perawat dalam merawat klien gangguan jiwa.

Hasil analisa didapatkan bahwa tingkat pendidikan responden yang terbanyak adalah DIII keperawatan yaitu berjumlah 40 orang $(71,4 \%)$. Dari pendidikan terakhir yang dimiliki sebagian besar responden dapat dilihat bahwa responden telah layak bekerja dirumah sakit. Menurut Dewan Pimpinan Persatuan Perawat Nasional Indonesia (DPP PPNI, 1999) yang dimaksud dengan perawat adalah seseorang yang telah menyelesaikan pendidikannya pada pendidikan formal keperawatan minimal lulusan DIII keperawatan.

Hasil analisa data mengenai lama responden bekerja hasil terbanyak berada pada rentang 1-5 tahun yaitu berjumlah 22 orang (39,3\%). Didukung oleh pernyataan Irawan (2010) bahwa perilaku caring seorang perawat tergantung pada apa yang dimiliki dalam diri perawat tersebut yaitu niat dan pengetahuan yang baik. Peneliti berpendapat bahwa banyaknya responden yang bekerja rentang 1-5 tahun merupakan penyesuaian dari peningkatan tipe rumah sakit yaitu peningkatan dari tipe rumah sakit $\mathrm{B}$ menjadi tipe rumah sakit A pada akhir tahun 2011 sehingga penerimaan tenaga CPNS atau PNS lebih banyak menyebabkan masih banyaknya responden yang masih belum lama bekerja dirumah sakit tersebut.

Hasil analisa menunjukkan bahwa motivasi kerja yang dimiliki responden mayoritas tinggi yaitu berjumlah 30 orang $(53,6 \%)$. Masih ada hampir sebagian perawat yang bekerja di Rumah Sakit Jiwa Tampan Provinsi Riau yang memiliki motivasi kerja yang rendah. Kecendrungan disebabkan masih banyaknya faktor-faktor yang mendukung motivasi perawat tersebut yang belum terpenuhi baik dari dalam diri maupun luar diri yang mampu mempengaruhi 
motivasi dalam berperilaku caring dan kinerja perawat. Hal ini sejalan dengan penelitian Amelia (2009) menyatakan bahwa kinerja perawat yang baik sangat terkait dengan motivasi kerja dari perawat tersebut, motivasi dianggap hal yang menentukan untuk menghasilkan sesuatu.

Hasil penelitian mengenai perilaku caring responden didapatkan bahwa sebanyak 29 orang $(51,8 \%)$ responden telah memiliki perilaku caring. Hasil analisa memperlihatkan masih ada sebagian dari perawat yang berperilaku tidak caring, Kecendrungan hal ini disebabkan ada banyak faktor yang mempengaruhi perilaku caring seseorang. Pernyataan ini didukung oleh Magareta (2009) bahwa perilaku caring perawat yang dirasakan pasien adalah bagaimana perawat aktif bertanya, berbicara lembut, memberi dukungan, responsif, terampil dan menghargai serta menjelaskan. Hal ini sejalan dengan penelitian yang dilakukan Irawan (2010) bahwa Perawat di rumah sakit daerah Provsu Medan lebih memperhatikan pentingnya perilaku caring, yang memiliki tujuan untuk meningkatkan pelayanan keperawatan ke arah yang lebih baik dan profesional.

Hasil analisa yang telah dilakukan dapat disimpulkan bahwa dengan motivasi kerja yang tinggi sebanyak 30 orang atau $53,6 \%$ perawat memiliki perilaku caring sebanyak 29 orang atau 51,8\% selanjutnya dilakukan analisa statistik dengan memakai uji Chi-square terdapat hubungan yang signifikan antara motivasi kerja terhadap perilaku caring perawat dengan nilai $p=0,001<\alpha(0,05)$.

Notoatmodjo (2007) mengemukakan motivasi merupakan dorongan dari dalam diri manusia untuk bertindak atau berperilaku. Hal ini sangat berkaitan dengan yang ada di dalam Potter dan Perry (2009) bahwa caring bersifat sangat personal, sehingga pengungkapan caring pada tiap klien berbeda. Peneliti menyimpulkan setiap dorongan yang mengarahkan perilaku yang dimiliki perawat dalam bekerja berbeda sehingga perawat dalam mengungkapkan perilaku caring yang dimilikinya kepada klien juga akan berbeda. Hal ini sejalan dengan penelitian yang dilakukan oleh Waskiyah (2011) mengenai hubungan antara motivasi kerja dengan perilaku caring perawat di Rumah Sakit Umum Kraton, Kabupaten Pekalongan menunjukkan hasil bahwa ada hubungan yang bermakna antara motivasi kerja dan perilaku caring perawat.

\section{KESIMPULAN}

Hasil penelitian ini menunjukkan terdapat hubungan yang bermakna antara motivasi kerja dengan perilaku caring pada perawat di ruang rawat inap Rumah Sakit Jiwa Tampan Provinsi Riau. Hal ini disebabkan oleh perilaku caring lebih erat kaitannya dengan motivasi kerja, karena perilaku seseorang tersebut dapat terlihat dari bagaimana niat atau dorongan serta bentuk kepribadian yang dimiliki responden itu sendiri.

\section{SARAN}

1. Disarankan bagi Institusi Rumah Sakit agar dapat melakukan pelatihan-pelatihan untuk perawat yang berkaitan dengan perilaku caring dalam melaksanakan asuhan keperawatan sehingga dapat meningkatkan mutu pelayanan.

2. Disarankan bagi Perawat agar dapat memilah kepentingan pribadi dan kepentingan bekerja untuk meningkatkan lagi motivasi kerja sehingga dapat meningkatkan perilaku caring perawat. Meningkatkan perilaku caring juga dapat meningkatkan mutu pelayanan yang diberikan perawat.

3. Disarankan bagi Peneliti Selanjutnya agar dapat lebih memperdalam penelitian ini dengan menambahkan variabel lainnya seperti kinerja perawat, dan dapat dikembangkan lagi dengan desain dan metode penelitian yang berbeda. Yaitu menggunakan jenis penelitian kualitatif dengan metode wawancara mendalam.

\section{KEPUSTAKAAN}

Dahlan, S, M. (2012). Statistik Untuk Kedokteran Dan Kesehatan. Jakarta: Salemba Medika.

Depkes R.I. (2010). Riset Kesehatan Dasar (Riskesdas) 2007. Jakarta: Badan Penelitian dan Pengembangan Depkes R.I.

Depkes R.I. (2011). Perawat Jiwa di Indonesia. Jakarta: Badan Penelitian dan Pengembangan Depkes R.I.

Hastono, S.P. (2010). Statistik Kesehatan. Jakarta: Raja Grafindo Pustaka.

Irawan, A. (2010). Perilaku caring perawat dalam memberikan asuhan keperawatan pada pasien gangguan jiwa di Rumah Sakit Jiwa Daerah Provinsi Sumatera Utara, Medan. Skripsi. Tidak dipublikasikan.

Magareta, M. (2010). Persepsi Pasien Tentang Perilaku Caring Perawat dalam Pealayanan Keperawatan di Ruang Maranatha 1. Skripsi. Tidak dipublikasikan.

Medical Record RSJ Tampan Provinsi Riau. (2012). Jumlah ruangan rawat inap dan tenaga perawat.Pekanbaru: RSJ Tampan Provinsi Riau.

Notoatmodjo, S. (2007). Promosi Kesehatan dan Ilmu Perilaku. Jakarta: Rineka Cipta. 
Notoatmodjo, S. (2010). Metode Penelitian Kesehatan. Jakarta: Rineka Cipta.

Nursalam. (2012). Manajemen Keperawatan :aplikasi dalam praktik keperawatan professional. Edisi 2. Jakarta: Salemba Medika.

Perry, A.G dan Potter, P.A. (2009).Buku Ajar fundamental Keperawatan Buku I Edisi 7.Jakarta:Salemba Medika.

PPNI, (2010), Pengertian Motivasi. http://innappni.or.id/index.php diakses pada tanggal 28 Oktober, 2012.
STIKes Hang Tuah Pekanbaru. (2012). Panduan Skripsi Program Sarjana. Pekanbaru: STIKes Hang Tuah Pekanbaru.

Wahyuni, S. (2010). Gambaran Tipe Empati Perawat Jiwa Di Rumah Sakit Jiwa Tampan Provinsi Riau. Skripsi. Tidak dipublikasikan.

Waskiyah, Y. (2011). Hubungan antara motivasi kerja dengan perilaku caring perawat di RSUD Kraton Kabupaten Pekalongan. Skripsi. Tidak dipublikasikan. 